\title{
Pain Management by the Family Physician: The Family Practice Pain Education Project
}

\author{
Edward T. Bope, MD, Alan B. Douglass, MD, Alan Gibovsky, MD, Tanya Jones, MD, \\ Laeth Nasir, MBBS, Trish Palmer, MD, Sunil Panchal, MD, \\ Francine Rainone, PhD, DO, Peter Rives, MD, Knox Todd, MD, and
}

James D. Toombs, MD

\begin{abstract}
Pain is a common complaint of patients who visit a family physician, and its appropriate management is a medical mandate. The fundamental principles for pain management are: placing the patient at the center of care; adequately assessing and quantifying pain; treating pain adequately; maximizing function; accounting for culture and gender differences; identifying red and yellow flags early; understanding and differentiating tolerance, dependence and addiction; minimizing side effects; and being familiar with and using CAM therapies when good evidence of efficacy exists. The pharmacologic management of pain requires thorough knowledge of nonsteroidal anti-inflammatory drugs, cyclo-oxygenase-2-specific inhibitors, and opioids. A table of equianalgesic dosages is useful because patients may need to move from one opioid to another. Accompanying this article are papers discussing 5 common pain disorders seen by family physicians, including: neck pain, low back pain, joint pain, pelvic pain, and cancer/end of life pain. The family physician who learns these principles of pain management and the algorithms for these common pain disorders can serve patients well. (J Am Board Fam Pract 2004;17:S1-12.)
\end{abstract}

Pain management is an important initiative today. Patients often present to their family physicians with short- and long-term pain episodes, making this setting ideally suited for addressing pain management. Because the family physician has the opportunity to both initially assess the patient and then provide continuing care, he/she can initiate prompt, appropriate pain control and then escalate or taper medications as the therapeutic response dictates.

From the Riverside Family Practice Residency Program, Riverside Methodist Hospital, Columbus, OH (ETB), Middlesex Hospital Family Practice Residency, University of Connecticut School of Medicine, Farmington (AD), Departments of Medicine and Public Health, Weill Medical College, Cornell University, New York, NY (AG), Department of Family Medicine, Morehouse School of Medicine, Atlanta, GA (TJ), Department of Family Medicine, University of Nebraska at Omaha (LN), Pisacano Leadership Foundation and the Department of Family and Preventive Medicine, University of Utah, Salt Lake City (TP), H. Lee Moffitt Cancer Center, University of South Florida, Tampa (SP), Department of Family Medicine, Montefiore Medical Center, Bronx, NY (FR), Pain Care Institute, Owensboro, KY (PR), Pain Medicine and Emergency Medicine Initiative, Rollins School of Public Health, Emory University, Atlanta, GA (KT), and Department of Anesthesia, University of Iowa Hospitals \& Clinics, Iowa City (JDT). Address correspondence to Edward T. Bope, MD, Program Director, Riverside Family Practice Residency Program, Riverside Methodist Hospital, 697 Thomas Lane, Columbus, OH 43214 (e-mail: bopee@ohiohealth.com).

\section{Definitions}

Pain is technically defined as "an unpleasant sensory and emotional experience associated with actual or potential tissue damage or described in terms of such damage." ${ }^{1}$ Acute pain often follows an injury but may also arise de novo as the result of structural degeneration, infection, or metabolic changes. This pain tends to abate as the tissues heal. Chronic pain, simply put, persists with time and is generally defined as lasting longer than 6 months. Pain is generally divided into 3 categories: nociceptive, neuropathic, and mixed. Nociceptive pain comes from body tissues that are injured and is further divided into somatic and visceral pain. Examples of somatic pain include osteoarthritis, rheumatoid arthritis, and fibromyalgia; visceral pain

The Family Practice Pain Education Project (FP-PEP) acknowledges an unrestricted educational grant from Pfizer to Cardinal Health to produce educational materials for primary care doctors about pain management. The information provided here is the opinions and research of the family physicians who served on FP-PEP. AG is a consultant to Pfizer, a member of their Speaker's Bureau, and a stockholder. TJ is an Occasional Lecturer on pain management for Pfizer, for which she receives a stipend, and has been a member of Pfizer's Primary Care Advisory Board on Pain Management.

This work was presented in part at the 2003 American Academy of Family Physicians (AAFP) Scientific Symposium. 


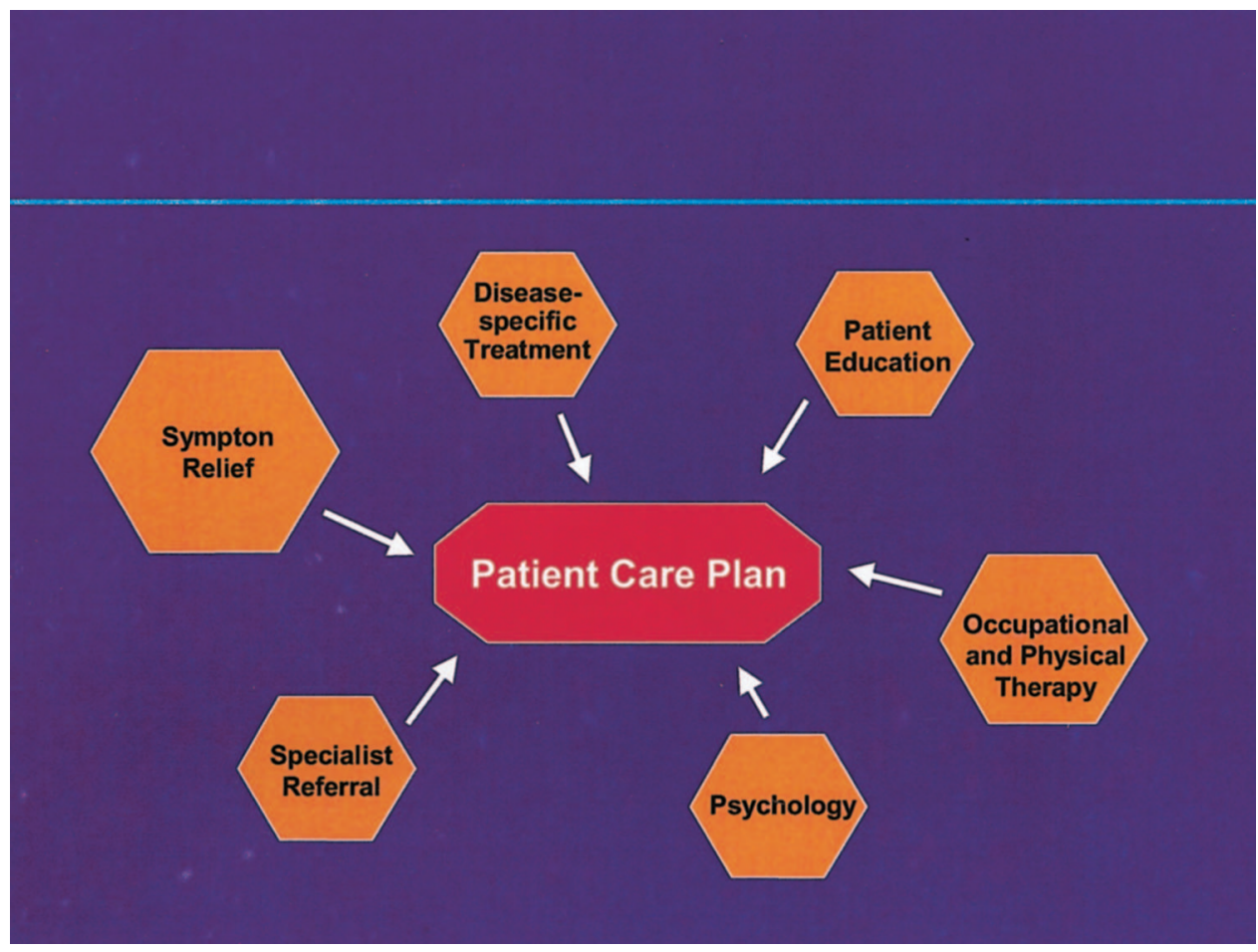

Figure 1. The patient as the center of care.

includes irritable bowel syndrome, pancreatitis, noncardiac chest pain, and abdominal pain. Neuropathic pain involves damage to the nervous system and often causes pain in the nerve dermatome, such as sciatica. Cancer and low back pain are disorders that may well be of mixed pain origin.

\section{The Prevalence of Pain}

Patients with pain are a part of nearly every medical specialty practice, and pain is among the most frequent reasons for visits to family physicians and other generalist providers. ${ }^{2}$ Among adults, 90\% suffer pain at least once a month and $42 \%$ have daily pain; $22 \%$ of all primary care patients have chronic pain. ${ }^{3}$ The most frequent types of pain for patients who see a primary care provider, as identified by the World Health Organization (WHO), include (in descending order of reported frequency): back pain, headache, joint pain, pain in the extremities, chest pain, abdominal pain, and pain elsewhere. ${ }^{4}$ Patients often have pain in more than one site.

\section{Fundamental Principles of Pain Management Principle 1: The Patient Should Be the Center of Care}

Pain is perceived only by the patient and is a highly individual experience. It is a complex phenomenon involving physical, psychological, and spiritual facets. Beginning with the initial visit, a key element in effective treatment is involving the patient in building and implementing a care plan (Figure 1). After a diagnosis is made, attention is often limited to surgical or pharmacological therapy. Although this may be appropriate for minor self-limited injuries, the care plan is necessarily more comprehensive in serious injuries or chronic pain. This plan should be tailored to the patient and designed to respect individual values and beliefs.

Development of the care plan must begin with assessment of the patient's understanding of the disorder. Education regarding the course of the illness and recovery process should be part of each visit. Beyond disease-specific therapy and pharmacological interventions, elements that should be included, whenever appropriate, are physical therapy, occupational therapy, and psychological or psychiatric assessment. The overarching objective is empowerment of the patient to play a major role in recovery and to set realistic goals for therapy.

\section{Principle 2: Assess and Quantify Pain}

Patient self-reporting is the most reliable indicator of the existence and intensity of pain. ${ }^{5,6}$ In eliciting these reports, clinicians should use standardized 
techniques and written instruments to improve both the recognition of pain as well as changes in pain over time.

Although pain is complex and multidimensional, tools used for rating pain need not be overly complex. In fact, the most common pain intensity assessment tool involves asking patients with pain the following simple question and recording their responses: "If zero is no pain and 10 is as bad as it could $b e$, what number from zero to 10 best represents your pain?"

This assessment tool is one of many Numerical Rating Scales (NRS), and its validity is well documented. ${ }^{7}$ The approach does not require any special materials, can be administered in person or over the telephone, and can be used for a wide diversity of patients. A child or adolescent probably has only limited experience with extreme pain, such as that of childbirth or renal stones, so they may over rate their pain on a numeric scale. For them, a picture scale (with associated numerical ratings) may be better.

Most patients suffering from pain have an underlying anatomic pain generator, although the pain experienced by an individual patient will be the product of the pain generator's output modified by a variety of patient factors, including other underlying medical problems, psychosocial issues, and affective disease. As part of patient assessment, localizing the pain generator can aid development of treatment plans.

\section{Principle 3: Treatment}

The end point of treatment is often a negotiation. Pain control modalities often do not fully relieve pain but can provide sufficient improvement to permit desired patient activities. Undertreatment sometimes occurs because of the physician's lack of familiarity with opioids and/or concerns about prescribing patterns that might prompt regulatory review. The use of nonopioid analgesics in a multimodal approach will reduce total opioid requirements and limit side effects. Examples of nonopioid analgesics used include capsaicin, nonsteroidal anti-inflammatory drugs (NSAIDs), cyclo-oxygenase-2 (COX-2)-specific inhibitors, tricyclic antidepressants, steroids, and anticonvulsants (Table 1 and Figure 2, step 1, described below).

Topical therapies have been used in a variety of pain settings but have been most popular in neuropathic pain or complex regional pain syndromes.
Capsaicin cream acts by depleting substance $\mathrm{P}$ in small primary afferent nociceptive neurons. Efficacy of the over-the-counter product is low, and compliance may be poor because of the burning effects; a higher strength is available by prescription. Clonidine, nitroglycerin, and dimethyl sulfoxide topical preparations have all been used. Some studies report success in reducing pain or increasing function with the use of these topical therapies. $^{8}$

Other procedures that reduce pain, such as neural blockade or neural ablation, will also reduce or eliminate the need for opioid analgesics. Neural ablation techniques include injection of alcohol or phenol, radio frequency (heat), cryoanalgesia, or surgical interruption of nociceptive pathways. Another approach is epidural or intrathecal drug delivery, allowing a reduced amount of drug to be directly delivered to the site of the pain generator, thereby decreasing systemic side effects.

In 1986, the World Health Organization developed a 3-step medication approach for the control of pain in cancer patients (Figure 2), and this has proven beneficial in other patients with pain. This "analgesic ladder" starts with the use of nonopioid analgesics, along with adjuvant medications, if needed, and progresses to the addition of opioids as needed for moderate to severe pain. Some authors have advocated adding a "fourth step" consisting of interventional procedures, such as nerve blocks, surgical procedures, and cognitive behavioral therapies to treat patients with intractable symptoms.

Mild pain may be defined as pain either described by the patient as mild or given a numeric rating of 1 to 3 on a scale of 0 to $10(0=$ no pain; $10=$ worst imaginable pain), lasting most of the day or recurring daily or several times a day. The actual number or description varies from person to person, depending on culture, prior experience, pain threshold, and other factors.

When treating mild pain, keep the following in mind:

- Realistic reassurance is a form of preventive medicine.

- Pain may trigger fears of death, disability, or disease progression. Support and education may be important even for mild pain, depending on the meaning attributed to it by the patient. Taking pain seriously builds trust and gives permission to the patient (and family) to reveal concerns 


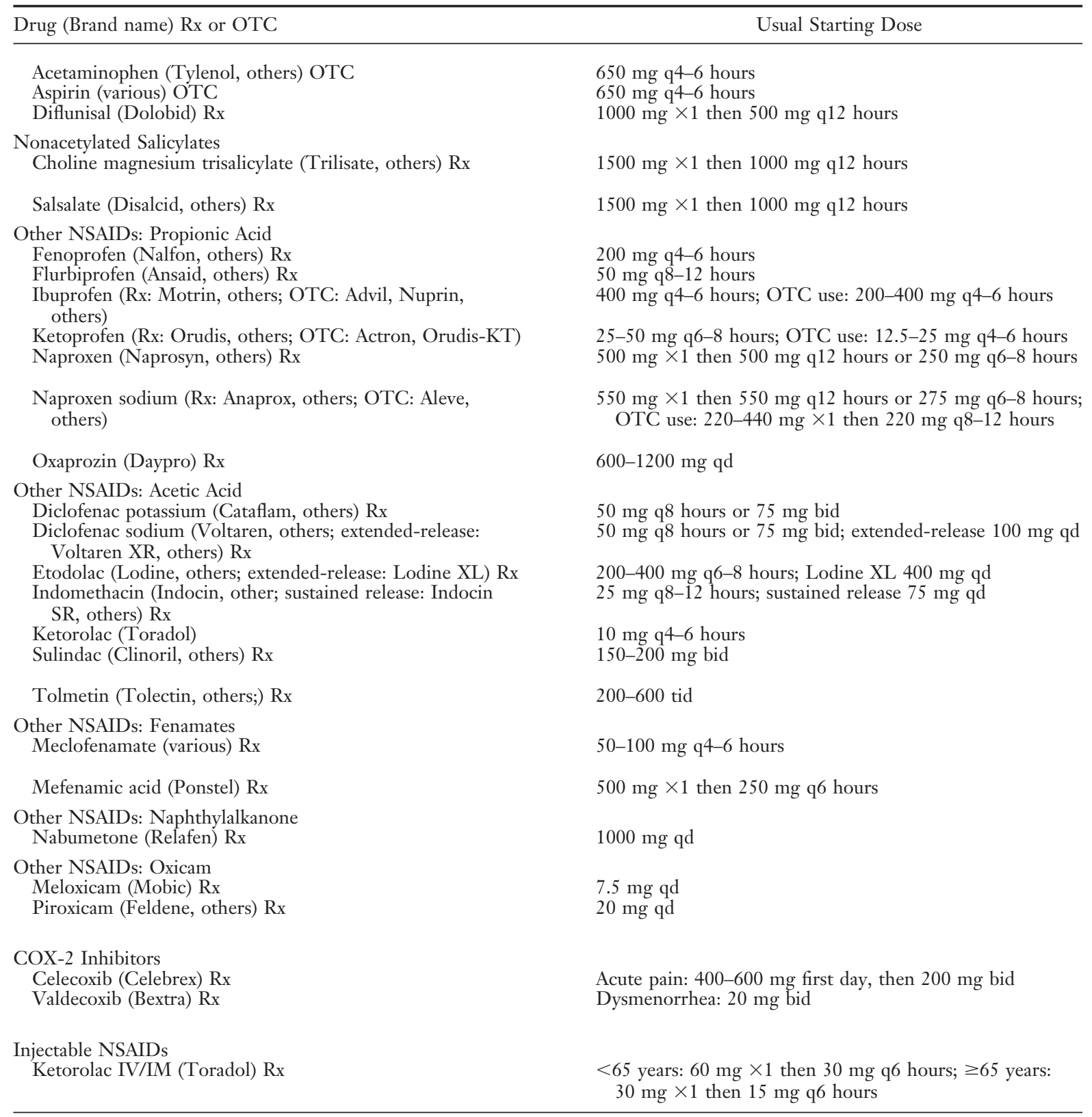

${ }^{*}$ Cost/day $=$ cost of usual daily dosage based on price listing at www.drugstore.com on 2003 Oct 21. Generic drugs were used whenever available.

qid, 4 times per day; tid, 3 times per day; bid, twice per day; qd, once per day; q, every.

and symptoms without worrying that the physician will be distracted from treating their illness. Stress that pain does not always equal harm.

- Nonpharmacologic therapy may be sufficient to resolve mild pain. Stress-reduction techniques, psychosocial counseling, and physical/occupational therapy may be adequate and appropriate. Complementary and alternative medicine (CAM) may also be indicated, especially if the patient prefers it.
- Offering medication provides an opportunity for education. Many patients have misconceptions about analgesics, and it is never too early to talk about issues such as tolerance, dependence, and addiction.

Patients with mild pain may be offered acetaminophen, NSAIDs, or COX-2-specific inhibitors (Table 1). If these agents are insufficient or cannot be used, a combination opioid/nonopioid 


\begin{tabular}{|c|c|c|}
\hline Maximum Daily Dose & Comments & Cost/day* \\
\hline $4000 \mathrm{mg}$ & $1000 \mathrm{mg}$ is more effective than $650 \mathrm{mg}$ in some patients & $<\$ 1.00$ \\
\hline $4000 \mathrm{mg}$ & May not be tolerated as well as some newer NSAIDs. & $<\$ 1.00$ \\
\hline $1500 \mathrm{mg}$ & Derived from salicylic acid. Little antipyretic activity & $\$ 2.80$ \\
\hline $3000 \mathrm{mg}$ & \multirow{2}{*}{$\begin{array}{l}\text { Effective anti-inflammatory drugs, but less effective analgesics than } \\
\text { aspirin. Have minimal antiplatelet effect and do not alter bleeding } \\
\text { time. Aspirin cross-sensitivity less likely to occur. }\end{array}$} & $\$ 3.00$ \\
\hline $3000 \mathrm{mg}$ & & $\$ 2.50$ \\
\hline $1200 \mathrm{mg}$ & $90 \%$ eliminated by the kidney. & $\$ 3.40$ \\
\hline $300 \mathrm{mg}$ & At high doses, monitor closely for side effects. & $\$ 1.00$ \\
\hline $2400 \mathrm{mg} ;$ OTC $1200 \mathrm{mg}$ & $200 \mathrm{mg} \approx 650 \mathrm{mg}$ aspirin or APAP. $400 \mathrm{mg} \approx$ codeine/APAP & $\$ 1.60$ \\
\hline $300 \mathrm{mg} ;$ OTC $75 \mathrm{mg}$ & $12.5 \mathrm{mg} \approx 200 \mathrm{mg}$ ibuprofen; $50 \mathrm{mg}$ superior to codeine/APAP & $\$ 3.60$ \\
\hline $1250 \mathrm{mg}$ first day then $1000 \mathrm{mg}$ & $\begin{array}{l}250 \mathrm{mg} \approx 650 \mathrm{mg} \text { aspirin with longer duration. } 95 \% \text { eliminated by } \\
\text { the kidney. }\end{array}$ & $<\$ 1.00$ \\
\hline $\begin{array}{l}1375 \mathrm{mg} \text { first day then } 1100 \mathrm{mg} \text {; } \\
\text { OTC } 660 \mathrm{mg}\end{array}$ & $\begin{array}{l}275 \mathrm{mg} \approx 650 \mathrm{mg} \text { aspirin with longer duration; OTC } 440 \mathrm{mg} \approx 400 \\
\mathrm{mg} \text { ibuprofen. } 95 \% \text { eliminated by the kidney. Naproxen sodium } \\
\text { may have less dyspepsia than naproxen }\end{array}$ & $<\$ 1.00$ \\
\hline $1800 \mathrm{mg}$ & Long serum half-life ( $42-50$ hours) & $\$ 1.66$ \\
\hline $150 \mathrm{mg}$ & May have less dyspepsia than the sodium salt. & $\$ 1.10$ \\
\hline $150 \mathrm{mg}$; for Voltaren XR $100 \mathrm{mg}$ & $\begin{array}{l}\text { Also available with misoprostol } 200 \mu \mathrm{g} \text { (Arthrotec } 50 \mathrm{mg}, 75 \mathrm{mg} \text { ) to } \\
\text { decrease GI toxicity. }\end{array}$ & $\$ 1.00$ \\
\hline $1200 \mathrm{mg}$; for Lodine XL $1000 \mathrm{mg}$ & $200 \mathrm{mg} \approx 650 \mathrm{mg}$ aspirin or APAP & $\$ 2.70$ \\
\hline $200 \mathrm{mg}$; for Indocin SR $75 \mathrm{mg}$ bid & Higher incidence of side effects. Also available in oral suspension. & $<\$ 1.00$ \\
\hline $40 \mathrm{mg}$ & $\begin{array}{l}91 \% \text { eliminated by the kidney. Use lower dose if }>65 \text { years or } \\
<50 \mathrm{~kg} \text {. Do not use }>5 \text { days }\end{array}$ & $\$ 3.70$ \\
\hline $400 \mathrm{mg}$ & Have few cases reporting less drug interaction with lithium & $<\$ 1.00$ \\
\hline $1800 \mathrm{mg}$ & $100 \%$ eliminated by the kidney. & $\$ 1.65$ \\
\hline $400 \mathrm{mg}$ & $\begin{array}{l}\text { Comparable with aspirin. Commonly used for dysmenorrhea. } \\
\text { Diarrhea is common }\end{array}$ & $\$ 1.10$ \\
\hline $1250 \mathrm{mg}$ & Effective in dysmenorrhea. Do not use $>1$ week & $\$ 5.20$ \\
\hline $2000 \mathrm{mg}$ & Can be given either qd or bid & $\$ 2.40$ \\
\hline $15 \mathrm{mg}$ & Dose-dependent COX-2/COX-1 inhibition & $\$ 2.00$ \\
\hline $20 \mathrm{mg}$ & $\begin{array}{l}\text { Long serum half-life ( } 50 \text { hours). High incidence of side effects, } \\
\text { especially in the elderly. }\end{array}$ & $<\$ 1.00$ \\
\hline $400 \mathrm{mg}$ & Contraindicated in sulfa allergy & $\$ 4.70$ \\
\hline $40 \mathrm{mg}$ & $\begin{array}{l}\text { Approved for osteoarthritis/rheumatoid arthritis and dysmenorrhea } \\
\text { only }\end{array}$ & $\$ 5.40$ \\
\hline $120 \mathrm{mg}$ & $\begin{array}{l}91 \% \text { eliminated by the kidney. Use lower dose if }>65 \text { or }<50 \mathrm{~kg} \text {. Do } \\
\text { not use }>5 \text { days }\end{array}$ & $\$ 7.99$ ea dose \\
\hline
\end{tabular}

drug regimen or a low dose of a short-acting opioid (for acute pain) or long-acting opioid (for chronic pain) may be started. In the short term, medications prescribed on an as-needed basis may be appropriate. However, if mild pain is continuous and bothersome, "as-needed" prescriptions are generally inappropriate, and a fixed dosing schedule should be used.

Even mild pain should be reassessed every few days to determine whether the treatment is adequate. If acute pain is adequately managed with the initial regimen, continue the therapy until resolution. If chronic pain is adequately managed, then institute maintenance therapy. Long-acting medications are preferred for chronic pain; however, a short-acting breakthrough medication should always be prescribed when changing from short- to long-acting opioids. Reassess the patient's pain level and ask about side effects at every subsequent visit.

If pain persists, and the patient is not taking medications, suggest medications. If the patient is 


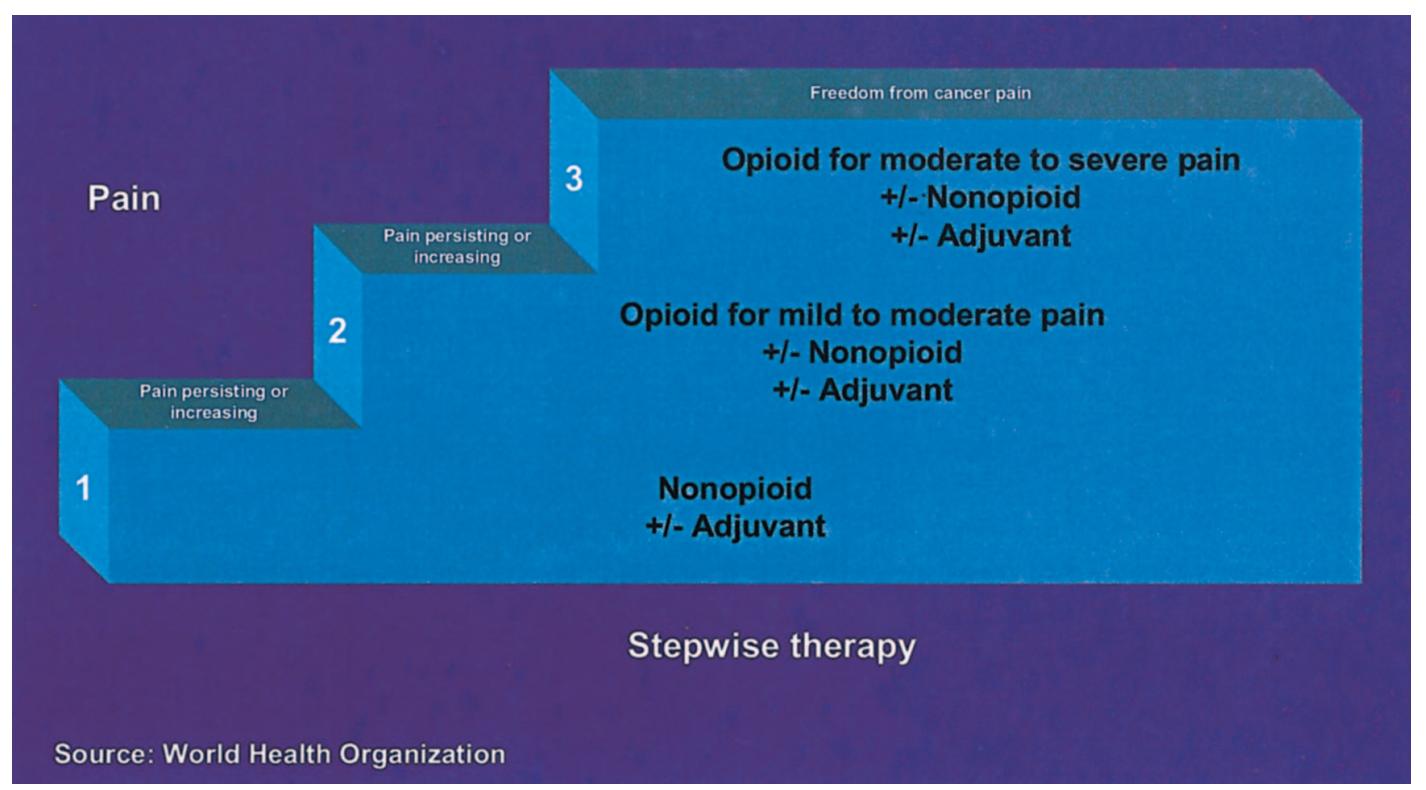

Figure 2. WHO analgesic ladder.

already taking medications but the pain is not adequately controlled, the options include increasing the dose of the current medication, adding an opioid if not present, adding an adjuvant medication or CAM modality, and exploring behavioral issues.
If an opioid is added, a combination medication such as acetaminophen/oxycodone may allow lower doses of both the opioid and the other agent (Table 2). Using lower doses may reduce the incidence of side effects, provided efficacy is not compromised.

Table 2. Commonly Used Step 2 Agents

\begin{tabular}{|c|c|c|c|}
\hline Drug & Examples of Brand Name & Usual Adult Dose* & $\operatorname{Cost}^{\dagger}$ \\
\hline \multicolumn{4}{|c|}{ Opioid Analgesic Combination (Controlled Drug Schedule) } \\
\hline Codeine/APAP (C-III) & $\begin{array}{c}\text { Tylenol \#2 15/300, Tylenol \#3 } \\
\text { 30/300, Tylenol \#4 60/300; } \\
\text { Liquid 12/120/5 mL (c-v) }\end{array}$ & $\begin{array}{l}60 \mathrm{mg} \mathrm{q} 3-4 \text { hours or } 1-2 \text { tab q4 } \\
\text { hours; } 15 \mathrm{~mL} \mathrm{q} 4 \text { hours }\end{array}$ & $\begin{array}{l}\$ 7-14 / 30 \mathrm{~s} \$ 6-10 / \\
120 \mathrm{~mL}\end{array}$ \\
\hline Codeine/aspirin (C-III) & $\begin{array}{l}\text { Empirin } \# 330 / 325, \text { Empirin } \# 4 \\
60 / 325\end{array}$ & $\begin{array}{l}60 \mathrm{mg} \mathrm{q} 3-4 \text { hours or } 1-2 \text { tab q } \\
4 \text { hours }\end{array}$ & $\$ 5-8 / 30 s$ \\
\hline Hydrocodone/APAP (C-III) & $\begin{array}{l}\text { Lorcet-HD 5/500, Lorcet plus } \\
\text { 7.5/650, Lorcet } 10 / 650 ; \text { Lortab } \\
\text { 2.5/500, 5/500, 7.5/500; } \\
\text { Vicodin 5/500, Vicodin ES } \\
\text { 7.5/750, Vicodin HP } 10 / 660 ; \\
\text { Lortab elixir } 2.5 / 167 / 5 \mathrm{~mL}\end{array}$ & $\begin{array}{l}10 \mathrm{mg} \mathrm{q} 3-4 \text { hours or } 1-2 \text { tab q } \\
3-4 \text { hours }\end{array}$ & $\$ 14-25 / 30 s$ \\
\hline Hydrocodone/ibuprofen (C-III) & Vicoprofen $7.5 / 200$ & 1 tab q 4-6 hours & $\$ 32.55 / 30 \mathrm{~s}$ \\
\hline Oxycodone/APAP (C-II) & $\begin{array}{l}\text { Percocet } 2.5 / 325,5 / 325,7.5 / 500 \\
\text { 10/650; Roxicet } 5 / 325,5 / 500 ; \\
\text { Tylox } 5 / 500\end{array}$ & $10 \mathrm{mg} \mathrm{q} \mathrm{3-4} \mathrm{hours}$ & $\$ 6-24 / 30 s$ \\
\hline Oxycodone/aspirin (C-II) & $\begin{array}{l}\text { Percodan-Demi 2.5/325, } \\
\quad \text { Percodan 5/325 }\end{array}$ & $10 \mathrm{mg} \mathrm{q} 3-4$ hours & $\$ 7-17 / 30 s$ \\
\hline $\begin{array}{l}\text { Propoxyphene napsylate/APAP } \\
\text { (C-IV) }\end{array}$ & $\begin{array}{l}\text { Darvocet-N } 5050 / 325, \\
\text { Darvocet-N } 100100 / 650\end{array}$ & $100 \mathrm{mg} \mathrm{q} 4$ hours & $\$ 9-16 / 30 s$ \\
\hline Propoxyphene/APAP (C-IV) & Wygesic $65 / 650$ & 1 tab q 4 hours & $\$ 6-9 / 30 s$ \\
\hline \multicolumn{4}{|l|}{ Other Step 2 Agents } \\
\hline Tramadol $^{\ddagger}$ & Ultram $50 \mathrm{mg}$ & 50-100 mg q 4-6 hours & $\$ 25 / 30 s$ \\
\hline Tramadol/APAP ${ }^{\ddagger}$ & Ultracet $37.5 / 325$ & $1-2$ tab q $4-6$ hours & $\$ 25 / 30 s$ \\
\hline
\end{tabular}

* The total dose of acetaminophen or aspirin should be $<4 \mathrm{~g} /$ day.

${ }^{+}$Cost based on generic pricing listed in 2001 Drug Topics Redbook.

${ }^{\ddagger}$ Not available in generic.

APAP, acetaminophen; q, every. 
Reassess the patient every 7 to 14 days, with careful monitoring for side effects until the pain is adequately controlled. Then reassess at every visit.

Set a time frame for assessing efficacy, because polypharmacy poses increased risks of drug interactions and side effects. Family physicians should review each patient's medication list regularly. Likewise, nonpharmacologic interventions should be discontinued if they are ineffective after several weeks.

Moderate pain may be defined as pain that is rated between 4 and 6 on a 0 to 10 scale or is described as moderate by the patient. When treating moderate pain, keep the following in mind:

- Peace of mind is a powerful adjuvant for pain relief. Peace of mind may be defined as freedom from fear, anger, and guilt. Pain is generally amplified by the presence of any of those emotions. Whenever pain is causing distress or interfering with baseline functioning, the transcendent domain should be explored for sources of suffering.

- Following the numbers is not enough. The standard for measuring adequate pain control is patient self-assessment. For some patients, especially those with chronic pain, a level between 4 and 6 may constitute adequate relief. For others, anything greater than a level of 2 is unacceptable.

- Moderate cancer pain requires urgent intervention. Interventions should begin at the time of complaint, along with an aggressive search for cause. In addition, as pain intensifies, increased attention should be paid to function and the level at which the patient finds pain relief acceptable.

Either alone or in combination, opioids are the pharmaceutical cornerstone of most moderate pain management. A short-acting opioid and bowel regimen is strongly recommended. Table 3 lists commonly used Step 3 opioids. Nonopioids, adjuvants, and CAM modalities may be used in combination with the opioid. Adjuvants are agents for which the primary indication is not for pain but are known to reduce pain in some circumstances. Titrate the analgesic regimen based on patient report; Tables 4 and 5 provide equianalgesic dosing information for morphine compared with other opioids.

Severe pain is defined as pain that is rated as 7 to 10 on a 0 to 10 scale or is described by the patient as severe. It should be kept in mind that severe pain requires emergent evaluation. Cancer patients who develop severe pain must be ruled out for oncologic emergencies, which will usually require hospitalization and specialty consultation. Rapidly titrate opioids, preferably delivering medication by the IV route. If the pain worsens or the patient gets less than $50 \%$ relief in 1 to 4 hours, re-evaluate the cause and the need for specialty consultation. Education, support, and stress management that focus on coping skills are crucial when a patient is experiencing severe pain.

\section{Principle 4: Maximize Function}

Patient assessment should focus on the complete person, rather than only the painful part, and on overall functionality of the patient. Functional impairment is defined as a compromised ability to perform a level of activity in the manner or within the range considered normal. It is common in patients with both acute and chronic pain syndromes and often results in decreased quality of life. However, different patients experiencing similar amounts of pain may have vastly different functionality. One may carry on an active and productive life, whereas another may enter a downward spiral of distress, disability, and despair. Although decreasing the quantity of patients' pain is a key goal of any treatment plan, of equal importance is ensuring that patients maximize their functionality. This requires careful attention to both physical and biopsychosocial arenas. ${ }^{?}$

\section{Principle 5: Account for Culture and Gender Differences}

There are a number of factors in the health care system that result in a disparity of both access to and treatment for pain based on culture, gender, and/or ethnicity. For example, results of a recent survey conducted by the University of Michigan Health System comparing black and white persons indicated that black persons reported more barriers in gaining access to effective pain care, and that black women were more likely than white women to have severe pain when they sought treatment. ${ }^{10}$

Logic would dictate that patients with similar pain symptoms, similar comorbidities, and no other significant complicating factors would undergo similar pain management treatment. However, in practice, particularly when there are cultural and gender differences between the patient and the physician, pain therapy can vary widely. Two major factors are involved that lead to this disparity in 


\begin{tabular}{|c|c|c|c|}
\hline Drug & Dosage Form (Brand Name) & Usual Adult Dosage & Cost* $^{*}$ \\
\hline \multicolumn{4}{|l|}{ Immediate-Release Product } \\
\hline \multirow[t]{4}{*}{ Morphine } & $\begin{array}{l}\mathrm{IV}: 1,2,4,5,8,10,15,25,50 \\
\quad \mathrm{mg} / \mathrm{mL}\end{array}$ & IV: $2-10 \mathrm{mg}$ & $\begin{array}{l}\$ 18-30 / 100 \text { s tab; } \$ 9-13 / 100 \\
\text { mL liquid; } \$ 15-30 / 12 \text { s supp }\end{array}$ \\
\hline & $\begin{array}{l}\text { Tablets: 15, } 30 \mathrm{mg} \text { (MSIR, } \\
\text { generic) }\end{array}$ & SC/IM: $10 \mathrm{mg} \mathrm{q} 4$ hours & \\
\hline & $\begin{array}{l}\text { Liquid: } 10 \mathrm{mg} / 5 \mathrm{~mL}, 20 \mathrm{mg} / 5 \\
\mathrm{~mL}, 20 \mathrm{mg} / \mathrm{mL}, 100 \mathrm{mg} / 5 \\
\mathrm{~mL} \text { (Roxanol, others) }\end{array}$ & PO: $10-30 \mathrm{mg} \mathrm{q} 4$ hours & \\
\hline & $\begin{array}{l}\text { Suppositories: } 5,10,20,30 \mathrm{mg} \\
\text { (various) }\end{array}$ & Rectal: $10-20 \mathrm{mg} \mathrm{q} 4$ hours & \\
\hline \multirow[t]{4}{*}{ Hydromorphone } & $\begin{array}{l}\mathrm{IV}: 1,2,4,10 \mathrm{mg} / \mathrm{mL} \\
\text { (Dilaudid, others) }\end{array}$ & IV/IM/SC: 1-4 q4-6 hours & $\$ 37-70 / 100$ s tab; $\$ 22 / 6$ s supp \\
\hline & $\begin{array}{l}\text { Tablets: } 1,2,3,4,8 \mathrm{mg} \\
\text { (Dilaudid, others) }\end{array}$ & PO: 2-6 mg q3-4 hours & \\
\hline & $\begin{array}{l}\text { Liquid: } 5 \mathrm{mg} / 5 \mathrm{~mL} \text { (Dilaudid, } \\
\text { others) }\end{array}$ & Rectal: $3 \mathrm{mg}$ q6-8 hours & \\
\hline & $\begin{array}{l}\text { Suppositories: } 3 \mathrm{mg} \text { (Dilaudid, } \\
\text { others) }\end{array}$ & & \\
\hline \multirow[t]{2}{*}{ Oxycodone } & $\begin{array}{l}\text { Tablets: } 5 \mathrm{mg} \text { (Percolone, } \\
\text { Roxicodone) }\end{array}$ & PO: $10-30 \mathrm{mg} \mathrm{q} 4$ hours & $\$ 30-36 / 100$ s tab \\
\hline & $\begin{array}{l}\text { Capsules: } 5 \mathrm{mg} \text { (OxyIR) } \\
\text { Liquid: } 5 \mathrm{mg} / 5 \mathrm{~mL} \\
\text { (Roxicodone), } 20 \mathrm{mg} / \mathrm{mL} \\
\text { (Roxicodone Intensol, } \\
\text { OxyFAST) }\end{array}$ & & \\
\hline \multirow[t]{3}{*}{ Meperidine $^{\dagger}$} & $\begin{array}{l}\mathrm{IV}: 10,25,50,75,100 \mathrm{mg} / \mathrm{mL} \\
\quad \text { (various) }\end{array}$ & $\begin{array}{l}\text { IV/IM/SC: } 50-100 \mathrm{mg} \mathrm{q} 3-4 \\
\text { hours }\end{array}$ & $\$ 68 / 100$ s tab \\
\hline & $\begin{array}{l}\text { Tablets: } 50,100 \mathrm{mg} \text { (Demerol, } \\
\text { various) }\end{array}$ & PO: $50-100 \mathrm{mg} \mathrm{q} 3-4$ hours & \\
\hline & $\begin{array}{l}\text { Liquid: } 50 \mathrm{mg} / 5 \mathrm{~mL} \\
\text { (Demerol, various) }\end{array}$ & & \\
\hline \multicolumn{4}{|l|}{ Sustained-Release Products ${ }^{\ddagger}$} \\
\hline $\begin{array}{l}\text { Morphine Sustained- } \\
\text { Release }^{\S}\end{array}$ & $\begin{array}{l}\text { SR Tablets: } 15,30,60,100 \text {, } \\
200 \mathrm{mg} \text { (MS Contin, } \\
\text { Oramorph SR) }\end{array}$ & $\begin{array}{l}\text { Not recommended for initial } \\
\text { therapy }\end{array}$ & $\begin{array}{l}\$ 90, \$ 171, \$ 334, \$ 511 / 100 s \\
\text { tabs }\end{array}$ \\
\hline $\begin{array}{l}\text { Oxycodone Controlled- } \\
\text { Release }^{\S}\end{array}$ & CR Tablets: $10,20,40,80 \mathrm{mg}$ & $\begin{array}{l}\text { Opioid-naive patients: } 10 \mathrm{mg} \mathrm{q} \\
12 \text { hours, and titrate }\end{array}$ & $\$ 124, \$ 238, \$ 422, \$ 793 / 100$ s \\
\hline Fentanyl Transdermal Patch & $\begin{array}{l}\text { Transdermal Patch: 25, 50, 75, } \\
100 \mu \mathrm{g} / \mathrm{hr} \text { (Duragesic) }\end{array}$ & $\begin{array}{l}\text { Opioid-naïve patients: } 25 \mu \mathrm{g} / \\
\text { hr every } 3 \text { days }\end{array}$ & $\$ 62, \$ 102, \$ 163, \$ 203 / 5$ s \\
\hline \multicolumn{4}{|c|}{ Opioids with Long Duration of Action ${ }^{\ddagger}$} \\
\hline Levorphanol & $\begin{array}{l}\text { Tablets: } 2 \mathrm{mg} \text { (Levo- } \\
\text { Dromoran) }\end{array}$ & PO: 2-4 mg q 6-8 hours & $\$ 87 / 100$ s \\
\hline Methadone & $\begin{array}{l}\text { Tablets: } 5,10,40 \mathrm{mg} \\
\text { (Dolophine, others, generic) }\end{array}$ & PO: $5-20 \mathrm{mg}$ Q 6-8 hours & $\$ 9, \$ 15, \$ 37 / 100$ s \\
\hline
\end{tabular}

* Cost based on generic pricing listed in 2001 Drug Topics Redbook.

${ }^{\dagger}$ Not recommended for cancer pain.

${ }^{\ddagger}$ Not recommended for initial therapy.

$\$$ Tablets are not to be chewed or crushed.

treatment: miscommunication and bias by both the physician and the patient.

Complicating the issue of pain management is the subjective nature of pain assessment, both as expressed by the patient and as interpreted by the physician. Beyond obvious communication barriers caused by language differences, the patient may provide nonverbal cues that are misleading to the physician. Further, in a "no pain, no gain" culture, particularly one in which patients have a lack of trust or even a fear of the system, they may be reluctant to imply that they either have significant pain or cannot "handle it" themselves. Depending on socioeconomic and insurance status, patients may be treated for chronic pain at an emergency center and only when they experience an acute exacerbation. They may seek physician care reluctantly and only after seeking relief using their traditional culture-centered pain remedies and/or "healers." Many times these alternative treatments can confound the treatment and the diagnosis of pain. In addition, depending on their culture, traditional belief systems may result in patients' foregoing pain treatment entirely or complying 


\begin{tabular}{|c|c|c|c|c|}
\hline \multirow[b]{2}{*}{ Drug (Common Trade Name) } & \multicolumn{2}{|c|}{$\begin{array}{l}\text { Dose (mg) Equianalgesic to } 10 \mathrm{mg} \\
\text { SC/IV Morphine }\end{array}$} & \multirow[b]{2}{*}{ SC/IV:PO ratio } & \multirow{2}{*}{$\begin{array}{l}\text { Duration of Action } \\
\text { (Hours) }\end{array}$} \\
\hline & SC/IV & $\mathrm{PO} / \mathrm{PR}$ & & \\
\hline Morphine (MSIR, Roxanol) & 10 & $30^{*}$ & $3: 1$ & $3-4$ \\
\hline Codeine (with aspirin or APAP) & 130 & $180-200$ & $1.5: 1$ & $3-4$ \\
\hline Hydrocodone (in Lortab, Vicodin, others) & NA & 30 & NA & $3-4$ \\
\hline Hydromorphone (Dilaudid) & 1.5 & 7.5 & $5: 1$ & $3-4$ \\
\hline Levorphanol (Levo-Dromoran) & 2 & 4 & $2: 1$ & $6-8$ \\
\hline Meperidine (Demerol) & 100 & 300 & $3: 1$ & 3 \\
\hline Methadone (Dolophine, others) & $\begin{array}{l}10 \text { for acute } \\
2-4 \text { for chronic }\end{array}$ & $\begin{array}{l}20 \text { for acute } \\
2-4 \text { for chronic }\end{array}$ & $2: 1^{\dagger}$ & $6-8^{\ddagger}$ \\
\hline $\begin{array}{l}\text { Oxycodone (Roxicodone, also in Percocet, } \\
\text { Percodan, others) }\end{array}$ & NA & 30 & NA & $3-4$ \\
\hline
\end{tabular}

${ }^{*} \mathrm{IV} / \mathrm{PO}$ ratio (1:3) is based on chronic dosing. IM/PO ratio of 1:6 for single dose or intermittent dosing.

${ }^{\dagger}$ Oral administration results in delayed onset and lower peak.

₹ Duration and half-life increase with chronic dosing.

APAP, acetaminophen; IM, intramuscular; PO, by mouth; SC, subcutaneous; IV, intravenous.

only selectively with prescribed therapeutic options.

Physicians' treatment decisions may be confounded by an inability to obtain needed information from the patient, as well as by perceptual biases (eg, viewing men as "stoic" and women as "hysterical"). Physicians may experience a level of discomfort with patients of a dissimilar culture; they may tend to stereotype patients based on culture and/or ethnicity as alcohol or drug abusers, or as physical abusers (men) or physically abused (women). Cultural, ethnic, and gender differences should be noted by physicians. They should strive to develop and implement in their practices culturally, ethni-

Table 5. Initial Duragesic Dose Based on Daily Oral Morphine Dose

\begin{tabular}{lc}
\hline Oral 24-hr Morphine (mg/day) & Duragesic Dose $(\mu \mathrm{g} / \mathrm{hr})$ \\
\hline $45-134$ & 25 \\
$135-224$ & 50 \\
$225-314$ & 75 \\
$315-404$ & 100 \\
$405-494$ & 125 \\
$495-584$ & 150 \\
$585-674$ & 175 \\
$675-764$ & 200 \\
$765-854$ & 225 \\
$855-944$ & 250 \\
$945-1034$ & 275 \\
$1035-1124$ & 300 \\
\hline
\end{tabular}

Source: Duragesic package insert. cally, and gender-sensitive intervention models that have applicability to the management of pain as well as other morbidities.

\section{Principle 6: Identify "Red Flags" and "Yellow Flags" Early}

"Red flags" denote symptoms or physical findings suggestive of a potentially serious cause for a patient's symptoms. They indicate the need for prompt and thorough evaluation. Some examples in neck or back pain include night sweats, fever, and weight loss, which are suggestive of an infectious or malignant process, and bladder or bowel incontinence suggestive of spinal cord compression. When red flags are noted, clinicians must expeditiously pursue a diagnostic workup.

"Yellow flags" denote adverse prognostic indicators. They signal the potential need for more complex management, intensive treatment, and/or earlier specialist referral. Some examples for whiplash-associated disorder include: severity of symptoms, older age, lack of full-time employment, and subjective initial complaints raising concerns about long-term prognosis. When yellow flags are present, clinicians need to be vigilant for deviations from the normal course of illness. ${ }^{11}$

Litigation or the involvement of workman's compensation programs pertaining to the patient's pain complaint are also often viewed by the physician as yellow flags. These issues should not, but often do, change the approach to diagnosis and treatment. Differences in documentation arise 
from the need to determine the source and cause of the problem, and whether it is an obvious acute injury or caused by overuse. Accuracy of diagnosis is also of great importance, for it helps in quantifying the projected time of disability and the specifics of activity restrictions. Imaging studies tend to be done earlier in an attempt to obtain a more specific diagnosis. Physical therapy is often used to get the patient off of restrictions more quickly. Subspecialty referrals are more common in this area of medicine both for diagnostic, prognostic, and treatment issues. Time and accuracy are essential in these cases.

\section{Principle 7: Understand and Differentiate Tolerance, Dependence, and Addiction}

Three inter-related and often-misunderstood phenomena are seen in patients receiving narcotic medications for substantial periods of time. The most common is physical dependence, which is a normal physiologic response to regular use of opioids for more than a few days. In patients who develop such dependence, abrupt discontinuation of the medication typically leads to a withdrawal syndrome. Tolerance is a condition in which progressively larger doses of the opioid in question are required to produce the same level of clinical analgesia; however, this phenomenon is usually limited to the initial phase of drug titration and is rarely seen thereafter. Often, what is thought to be tolerance is actually worsening of the pain condition with consequently greater medication requirements.

Addicts crave the drug, seek after the drug for its euphorigenic effects, and excessively or persistently use despite adverse consequences. Addiction is relatively rare in patients who receive opioids for an extended period, and may be related at least in part to a genetic predisposition to the condition.

\section{Principle 8: Minimize Side Effects}

Traditional nonsteroidal anti-inflammatory drugs (NSAIDs) are widely used in the treatment of pain. Their use, however, is often limited by the frequency of side effects, the most common of which include dyspepsia, peptic ulceration (gastric more often than duodenal), hemorrhage, and perforation. Because of the severity of these potential problems a variety of preventive strategies have been proposed.

\section{Prescribe NSAID Alternatives for High-Risk Patients}

This approach may be used in those patients who fall into one or more "risk groups," such as the elderly, those on concurrent corticosteroids, those with a history of peptic ulcer disease or significant NSAID-induced dyspepsia, or those with comorbid conditions such as cardiac disease. COX-2-specific inhibitors or acetaminophen are reasonable alternatives. In one trial, 688 patients with rheumatoid arthritis (mean age of 60) were randomly assigned to celecoxib, naproxen, or placebo for 12 weeks. All patients had endoscopy, and the rates for gastroduodenal ulcers for patients on celecoxib were similar to placebo (4\%) and significantly less than for those on naproxen $(26 \%) .^{12}$

\section{Prescribe NSAIDs with Meals}

This approach reduces the incidence and severity of dyspepsia but may be insufficient to prevent occult bleeding. Guaiac-positive stools are common even on low-dose aspirin therapy. Patients on NSAIDs need to be carefully monitored for symptoms of dyspepsia.

\section{Use Gastric Cytoprotection}

Misoprostol (a synthetic prostaglandin E1 analog), proton pump inhibitors, and histamine-2 blockers have all been shown to protect the gastric mucosa from the irritating effects of NSAIDs. Concomitant use of misoprostol has been shown to cause a $50 \%$ reduction in upper gastrointestinal adverse events in patients taking NSAIDs. ${ }^{13}$

Opioids are often used when NSAIDs and COX-2-specific inhibitors are not adequate for pain control. The great advantage of opioids over other pain medications is that there is no ceiling effect for analgesia; increased doses produce increased pain control. The dose-limiting step for opioids is dictated by the development of intolerable side effects. The major troublesome side effects of opioids are constipation; nausea and vomiting; sedation or other cognitive impairment; delirium; and others (space limitations preclude discussing every side effect). Fortunately, with aggressive management most patients become tolerant, to differing degrees, to these effects in 2 to 3 days, with the exception of constipation.

Because of the uniform side effect of constipation, always begin a bowel regimen when starting an opioid (Table 6). In addition, reinforce the 


\begin{tabular}{|c|c|c|}
\hline Class & Drug and Dosage & Estimated Cost/Dose* \\
\hline \multirow[t]{2}{*}{ Stimulant Laxatives } & Bisacodyl (Dulcolax, Correctol, others): 5-10 mg orally & $\$ 0.30-0.60$ \\
\hline & Senna (Senokot, others): $17.2 \mathrm{mg}$ at bedtime & $\$ 0.15-0.30$ \\
\hline \multirow[t]{3}{*}{ Osmotic Laxatives } & $\begin{array}{l}\text { Lactulose (Cephulac, others): } 15-30 \mathrm{~mL} \text { bid (may be administered } \\
\text { orally or rectally) }\end{array}$ & $\$ 0.62-1.25$ \\
\hline & Polyethylene glycol (MiraLax): $17 \mathrm{~g} /$ day in $8 \mathrm{oz}$ of water & $\$ 1.30$ \\
\hline & $\begin{array}{l}\text { Sorbitol } 70 \% \text { solution: } 15-30 \mathrm{~mL} \text { bid (may be administered orally or } \\
\text { rectally) }\end{array}$ & $\$ 0.25-0.50$ \\
\hline Emollient Laxatives & Docusate (Colace, others): $200-800 \mathrm{mg} /$ day in 2 divided doses & $\$ 0.05-0.20$ \\
\hline Combination Agents & $\begin{array}{l}\text { Docusate }(50 \mathrm{mg}) \text { plus senna }(8.6 \mathrm{mg}) \text { tablets (Senokot-S, others): } \\
2-4 \text { tablets once or twice daily }\end{array}$ & $\$ 0.30-0.60$ \\
\hline
\end{tabular}

* Cost is estimated using prices listed at www.drugstore.com (2004 Mar). Generic drugs were used whenever available. bid, twice daily.

importance of ingesting sufficient fluids and fiber, if this is possible. If there have been no bowel movements for 3 days, consider obstruction. If the history indicates stool is hard and difficult to pass, first treat any identifiable reversible causes, such as: dehydration, impaired access to toilet/commode, and constipation caused by medications that can be discontinued. If no reversible causes are identified, a digital rectal examination is the most cost-effective diagnostic tool. When a digital examination indicates a bowel full of hard stool, high enemas are often sufficient. If not, another option is to premedicate with analgesic and sedation, then digitally disimpact. If the bowel is empty and ballooned, there may be a high impaction and a high magnesium enema may resolve the problem. If the bowel is only partially full, it is probably a result of low intake of fluid and fiber, so these dietary factors should be maximized.

\section{Principle 9: Become Familiar with CAM Therapies and Use Them Where There Is Good Evidence of Efficacy}

Americans frequently use CAM therapies. Studies of treatment efficacy are ongoing, but strong evidence currently exists to support only a limited number of these therapies. The determination of placebo effect is a particular challenge when a subjective symptom such as pain is measured. Symptoms of pain for both the study group and control group have a tendency to improve over time, so it is not always clear how to measure improvement. Placebo improvement rates can be very high. The astute physician will discuss CAM therapies openly with patients but also be knowledgeable about ev- idence of efficacy and remain alert to the potential for therapies that might not be compatible.

\section{Principle 10: Recognize and Treat the Psychological Aspects of Pain}

Pain, either acute or chronic, can have psychological consequences. Acute pain causes a survival or "fight or flight" response. Common emotions are anger, regret, or blame. Acute pain is usually forgotten over time although certain stimuli may trigger recall. The pain can be severe enough to be "traumatic" giving rise to residual psychological issues. Chronic pain is experienced as a constant stressor. It can trigger psychological responses such as irritability, disturbed sleep, and altered mood. Depression is not uncommon and shares those symptoms with the addition of feelings of hopelessness and helplessness. Standard depression screening tools can be useful in recognizing coexisting depression.

Management of the psychological aspects of pain includes: support for the patient and family, counseling, and medication when needed. Antidepressant medications are useful for both depression and neuropathic pain.

\section{Conclusion}

Pain relief is an important agenda for the 21st century. The fundamental principles of pain management discussed in this article should encourage the physician to place the patient at the center of care and assess and treat pain appropriately, using a balanced and inclusive approach. Physicians should be alert for potential complications of therapy and manage them appropriately. Keeping the patient as 
the center of pain management as well as considering the influence of culture and gender differences will help achieve the proper therapeutic relationship. Assessing and quantifying pain and then treating it adequately are the goals of good care. Avoiding or managing the side effects of pain medication is worth the effort. The family physician has an important role in the control of pain for most patients.

\section{References}

1. Merskey H. Classification of chronic pain, descriptions of chronic pain syndromes and definitions of pain terms. Pain 1986;(Suppl 3):510-24.

2. Green LA, Phillips RL, Fryer GE. The nature of primary medical vare. In: Jones $\mathrm{R}$, Britten $\mathrm{N}$, Culpepper L, Gass D, Grol R, Mont D, editors. Oxford textbook of primary medical care. London: Oxford University Press; 2003.

3. Arthritis Foundation [homepage on the Internet]. Atlanta (GA): Arthritis Foundation; 1999. Pain factsheet. Pain in America: highlights from a Gallup survey [about 2 screens]. Available from: http://www. arthritis.org/conditions/speakingofpain/factsheet.asp

4. Gurege O, VanKoff M, Simon G, Gaten R. Persistent pain and well being - a World Health Organization study in primary care. JAMA 1998;280: $147-51$

5. Acute pain management: operative or medical procedures and trauma, Part 1. Agency for Health Care Policy and Research. Clin Pharm 1992;11: 309-31.

6. Acute pain management: operative or medical procedures and trauma, Part 2. Agency for Health Care Policy and Research. Clin Pharm 1992;11:391-414.
7. Jensen MP, Karoly P. Self-report scales and procedures for assessing pain in adults. In: Turk DC, Melzack R, editors. Handbook of pain assessment. New York: Guilford Press; 1992. p. 135-151.

8. Knobler RL. Myofascial pain: evaluation and treatment strategies: a focus on brachial plexus traction injury (neurogenic thoracic outlet syndrome). In: Tollison CD, Satterthwaite JR, Tollison JW, editors. Practical pain management, 3rd ed. Philadelphia: Lippincott Williams \& Wilkins; 2002. p. $570-9$.

9. Simmonds MJ, Peat JH. Rehabilitation therapies in pain and disability management: an activity driven biopsychosocial model of practice. In: Tollison CD, Satterthwaite JR, Tollison JW, editors. Practical pain management, 3rd ed. Philadelphia: Lippincott Williams \& Wilkins; 2002. p. 120-34.

10. Bound J, Waidman T, Schoenbaum M, Bingenheimer J. The labor market consequences of race differences in health. PSC Research Report 03-535. Ann Arbor (MI): Populations Studies Center at the Institute for Social Research, University of Michigan; 2003. Available at: http://psc.isr.umich.edu/ pubs/papers/rr03-535.pdf

11. Guidelines for the management of whiplash-associated disorders. Sydney, Australia: New South Wales Motor Accidents Authority; 2001. Available at: http://www.maa.nsw.gov.au/pdfs/whip_mgt_ summary_guide.pdf

12. Simon LS, Weaver AL, Graham DY, et al. Antiinflammatory and upper gastrointestinal effects of celecoxib in rheumatoid arthritis: a randomized controlled trial. JAMA 1999;24;282:1921-8.

13. Goldstein JL. Who needs prophylaxis of nonsteroidal anti-inflammatory drug-induced ulcers and what is optimal prophylaxis? Eur J Gastroenterol Hepatol 2000;12 Suppl 1:S11-5. 